\title{
Zolpidem Tartrate
}

National Cancer Institute

\section{Source}

National Cancer Institute. Zolpidem Tartrate. NCI Thesaurus. Code C29553.

The tartrate salt of an imidazopyridine with non-benzodiazepine benzodiazepine-receptor agonist and sedative-hypnotic activities. Zolpidem binds selectively to the alpha 1 subunit of the omega-1 (BZ1) receptor of the gamma-aminobutyric acid type A (GABA-A) receptor-chloride ionophore complex, thereby opening neuronal chloride channels, hyperpolarizing neuronal cell membranes, and inhibiting neuronal firing. In contrast, benzodiazepines non-selectively bind to and activate all omega receptor subtypes, exhibiting anticonvulsant and myorelaxant activities in addition to a sedative-hypnotic activity. 